\title{
Análise da implementação de uma estratégia de investimento em ações baseada em um instrumento de apoio à decisão
}

\section{Maurício Vasconcellos Leão Lyrio \\ Sociedade Educacional de Santa Catarina (SOCIESC) mauriciovll@gmail.com \\ Wlademir Prates \\ Universidade Federal de Santa Catarina \\ wrprates@yahoo.com}

\section{Marcus Vinícius}

Andrade de Lima

Universidade Federal de Santa Catarina

marcus.lima@cse.ufsc.br

\section{Rogério João Lunkes}

Universidade Federal de Santa Catarina

lunkes@cse.ufsc.br

\section{Resumo}

O presente estudo analisa a interface entre dois campos disciplinares: finanças e pesquisa operacional. Nesse sentido integra duas abordagens de análise de investimentos - técnica e fundamental, bem como as preocupações de um investidor no momento de alocação de recursos em uma estratégia de investimento em ações do tipo Buy \& Hold. De caráter exploratório e descritivo, o estudo utiliza como instrumento de intervenção a Metodologia Multicritério de Apoio à Decisão (MCDA). Como resultados, ficou evidenciado que o instrumento de intervenção utilizado, aliado à uma estratégia de investimentos pré-definida, foi capaz de suportar o decisor no momento de alocação de recursos, gerando uma rentabilidade de $25.14 \%$ no acumulado, contra uma rentabilidade negativa de $-13.41 \%$ do IBOVESPA no mesmo período. Com o objetivo de conferir a robustez dos resultados, foram realizadas regressões do modelo CAPM tanto com dados semanais quanto diários, sendo que o teste $t$ realizado nos coeficientes da regressão se mostrou significativo à $1 \%$ para o retorno anormal dos dados semanais e à $0.1 \%$ para o retorno anormal dos dados diários, além disso, a estatística $t$ foi positiva nos dois casos, indicando a presença de um retorno anormal positivo, ou seja, a carteira aqui proposta superou o seu benchmark.

Palavras chave: análise de investimentos, análise fundamental, análise técnica, metodologia MCDA-C 


\title{
Analysis of the implementation of a stock investment strategy based on a de- cision aid tool
}

\begin{abstract}
The present study analyzes the interface between two disciplinary fields - finance and operational research. In this sense, it integrates two approaches to investment analysis - fundamental and technical, as well as an investor's concern at the time of resources allocation in a Buy \& Hold investment strategy. The study uses the Multicriteria Decision Aid (MCDA) as an instrument of intervention. As for results, it was evident that the instrument of intervention used, together with a pre-defined investment strategy, was able to support the decision maker at the time of allocation of resources, generating an accumulated return of $25.14 \%$ in the period, compared with a negative return $-13.41 \%$ of the Bovespa index in the same period. In order to check the robustness of results, regressions were performed with both the CAPM model as daily and weekly data, and the t test performed on the coefficients of the regression was significant at $1 \%$ for the abnormal return of weekly data and $0.1 \%$ for the return of abnormal daily data; in addition, the t-statistic was positive in both cases, indicating the presence of abnormal positive feedback, i.e., the portfolio proposed here outperformed its benchmark.
\end{abstract}

Keywords: investments analysis, fundamental analysis, technical analysis, MCDA-C methodology

\section{Análisis de la aplicación de una estrategia de inversión con base en una herra- mienta de apoyo a las decisiones}

\section{Resumen}

Este estudio analiza la relación entre dos disciplinas, a saber, las finanzas y la investigación operativa. En consecuencia, integra dos enfoques para el análisis de inversiones - fundamental y técnica-, así como las preocupaciones de un inversionista en el momento de la asignación de los recursos, con el fin de analizar los resultados de una estrategia de inversión en acciones Buy \& Hold. El estudio utiliza como herramienta de intervención el MCDA (Ayuda a la Decisión Multicriterio). Como hallazgos, se hizo evidente que el instrumento de intervención utilizado, junto con una estrategia de inversión previamente definidos, fue capaz de apoyar la toma de decisiones en el momento de la asignación de los recursos, generando una rentabilidad del $25.14 \%$ en el año, frente a una rentabilidad negativa $-13.41 \%$ del índice Bovespa en el mismo período. Con el fin de comprobar la solidez de los 
hallazgos, las regresiones se realizaron con el CAPM tanto como datos de diario y semanal, y la prueba de la t realizada en los coeficientes de la regresión fue significativa al $1 \%$ para el rendimiento anormal de los datos semanales y $0.1 \%$ para el rendimiento anormal de los datos diarios, además, la estadística t fue positiva en ambos casos, lo que indica la presencia de retroalimentación positiva anormal, es decir, la cartera propuesta aquí batió a su referencia.

Palabras clave: análisis de inversión, análisis fundamental, análisis técnica, metodología MCDA-C

\section{Introdução}

Entre as decisões financeiras estão as decisões de investimento. Tais decisões são constantemente tomadas tanto por organizações quanto por indivíduos. Este tipo de decisões é amplamente observado no dia-a-dia daqueles que, de alguma forma, estão envolvidos com tomada de decisão no mercado de capitais. Neste contexto é comum que os investidores enfrentem dificuldades em aplicar estratégias de sucesso no que diz respeito as suas decisões de investimento. Os práticos de mercado comumente se deparam diante do trade-off existente entre as chamadas análise técnica e análise fundamental. Ambas as abordagens fornecem subsídios para a tomada de decisões de investimento no mercado de capitais. De referir que a análise técnica focaliza-se nas variações dos preços no mercado e na busca de padrões destas movimentações, enquanto que a análise fundamental se concentra nos fundamentos da empresa, ou seja, em indicadores contábeis, financeiros e de mercado.

Embora possam existir investidores que considerem excludentes as duas abordagens de análise citadas, podemos considerá-las como complementares. Tal argumento justifica-se quando tratamos a análise fundamental como base para a escolha das melhores empresas para se investir em termos de fundamentos e a análise técnica como uma sinalização do melhor momento para montar uma posição compradora ou vendedora em determinado ativo. Neste sentido, Oberlechner (2001) comenta que um dos resultados de sua pesquisa foi de que os investidores utilizam tanto a análise fundamental quanto a análise técnica / gráfica para tomarem suas decisões. Contudo, cabe destacar que Oberlechner (2001) estudou o mercado de câmbio e que a análise fundamental para este caso se difere da utilizada no mercado de ações, principalmente a respeito dos indicadores que são utilizados. 
Considerando este contexto, o presente estudo visa integrar essas duas abordagens - técnica e fundamental, bem como as preocupações de um investidor no momento de alocação de recursos, por meio de um modelo multicritério de apoio à decisão. O modelo proposto está fundamentado na vertente da pesquisa operacional conhecida como Decision Aid (DA), mais especificamente nos métodos multicritério de apoio à decisão (MCDA). Sendo assim, o objetivo deste trabalho é analisar os resultados de uma estratégia de investimento em ações do tipo Buy \& Hold, baseada em um modelo multicritério de apoio à decisão. Ademais, surge a seguinte questão: é possível obter sucesso com uma estratégia de investimento em ações baseada em um modelo de apoio à decisão que considere simultaneamente as abordagens técnica e fundamental e as particularidades do perfil do investidor no momento de alocação dos recursos em carteira?

A relevância deste estudo justifica-se, pois muitos dos indicadores (tanto técnicos / gráficos quanto fundamentais) utilizados pelos práticos de mercado são também estudados na academia, principalmente na busca de evidências empíricas que fortaleçam a hipótese de que a escolha de empresas com bom desempenho nos indicadores pode trazer bons retornos aos acionistas. Sendo este um tema bastante difundido tanto na academia quanto em meio aos profissionais do ramo, esta pesquisa distingue-se por utilizar uma abordagem Multicritério de Apoio à Decisão (MCDA) para escolher ativos a serem incluídos em uma carteira com base em diversos indicadores tanto da escola de análise fundamental quanto da escola técnica de precificação de ativos.

Após esta seção introdutória, o trabalho está organizado da seguinte forma: referencial teórico, onde são apresentadas as teorias que serviram de base para a elaboração deste estudo; metodologia de pesquisa, na qual é apresentado o enquadramento metodológico do estudo, bem como o instrumento de intervenção adotado (a metodologia MCDA) e os procedimentos para coleta e análise dos dados; apresentação e discussão dos resultados e, por fim, são apresentadas as considerações finais. 


\section{Referencial teórico}

O referencial teórico do presente estudo se desdobra em três eixos, a saber: análise fundamental; análise técnica; e estudos anteriores sobre a MCDA aplicada às finanças. Os dois primeiros eixos se dedicam à apresentação dos conceitos e premissas das duas principais escolas de análise de investimentos em ações. $\mathrm{O}$ último eixo, por sua vez, se dedicará a apresentar a contribuição da MCDA nas pesquisas em finanças, bem como estudos anteriores que adotam metodologia semelhante na condução de pesquisas na área.

\section{Análise fundamental}

Este tipo de análise costuma avaliar ações de empresas com base nos seus dados financeiros fundamentais, ou seja, procura precificar ações de empresas com base na análise de demonstrativos financeiros e contábeis. Dentro deste contexto diversos indicadores são vastamente utilizados pelo mercado a fim de que o propósito de precificar e avaliar ativos seja cumprido. Dessa forma, os próximos parágrafos apresentam trabalhos publicados no Brasil e exterior onde a análise fundamental foi de alguma forma abordada. Comumente, na academia, o estudo de variáveis fundamentais está associado com a compreensão de como estas variáveis influenciam as oscilações dos preços das ações (retornos), como pode ser verificado nos próximos parágrafos.

Em um estudo realizado no Japão, Chan, Hamao e Lakonishok (1991) procuraram entender o comportamento de algumas variáveis fundamentais e estudar a influência destas variáveis sobre os retornos esperados. As variáveis explicativas utilizadas foram rentabilidade, tamanho, valor patrimonial/preço (book to market) e o rendimento do fluxo de caixa (cash flow yield). O que os autores encontraram como principal resultado foi que o indicador valor patrimonial/preço e o rendimento do fluxo de caixa foram as variáveis com maior impacto positivo e significativo nos retornos esperados. Em termos metodológicos, os autores basearam suas análises e conclusões em regressões. Mais especificamente, os autores utilizaram o método SUR (Seemingly Unrelated Regressions) ${ }^{1}$.

${ }^{1}$ Ver Zellner (1962) para maiores detalhes sobre Seemingly Unrelated Regressions. 
Os renomados autores Fama e French procuraram entender as oscilações nos preços de ações considerando estes como uma função da variável dividend yield (Fama \& French, 1988). De acordo com os resultados obtidos os autores constataram que o dividend yield explica menos que 5\% da variância dos retornos em períodos mensais e quadrimestrais. No entanto, aumentando a periodicidade dos dados para dois a quatro anos, os autores observaram que a variância dos retornos é explicada em $25 \%$ pelo dividend yield. Os autores chegaram a estas conclusões com base em regressões e no valor de $\mathrm{R}^{2}$.

Fama e French (1992) foram além da relação entre retornos e dividend yield apresentada em Fama e French (1988). Em 1992 os autores utilizaram as variáveis fundamentais tamanho (medida pelo valor de mercado da companhia), alavancagem (através de indicadores de endividamento), índice book-to-market (B/M), lucro por ação/preço (LPA/P), além da variável $\beta$ de mercado, bastante conhecida por fazer parte do tradicional modelo CAPM. Estas variáveis foram utilizadas com o propósito de verificar se elas explicam as variações nos preços. Para cumprir o propósito da pesquisa os autores utilizaram principalmente análises de regressão e correlações. Entre os resultados encontrados os autores perceberam que o $\beta$ de mercado parece não ajudar a explicar os retornos (Fama \& French, 1992). Por outro lado, quando foram realizadas regressões uni-variadas do tamanho, alavancagem, LPA/P e B/M contra os retornos, a significância foi forte. Nos testes multivariados os autores obtiveram uma relação negativa entre tamanho e retorno e uma forte relação positiva entre $\mathrm{B} / \mathrm{M}$ e os retornos. Além disso, os autores comentam que a variável B/M possui um papel forte na explicação dos retornos (Fama \& French, 1992). Se uma empresa possui um alto valor de B/M (maior que 1) para suas ações significa que estes ativos estão "baratos", isto é, o preço contábil da ação é maior que o preço de mercado. Sendo assim, a explicação de Fama e French (1992) para uma relação positiva desta variável com os retornos pode estar relacionada com os fatores de risco de investir na empresa. Os autores comentam que "empresas que o mercado julga terem prospectos pobres, caracterizadas aqui por baixos preços das ações e um elevado valor de $\mathrm{B} / \mathrm{M}$, tem retornos esperados maiores (são penalizadas com um alto custo de capital) em relação às empresas com prospectos mais robustos" (Fama \& French, 1992, p. 428).

Em Fama e French (1995) os autores procuraram encontrar fundamentos para a existência da relação empírica entre o retorno médio de uma ação e o seu tamanho e entre o retorno médio e o índice B/M. Para procurar explicar estas relações os autores levantam duas hipóteses: (i) deve haver fatores de risco comuns nos retor- 
nos associados com o tamanho e com o indicador B/M; (ii) os padrões do tamanho e do $\mathrm{B} / \mathrm{M}$ nos retornos devem ser explicados pelas variações nos lucros. Como resultados os autores confirmaram a existência de uma relação entre os lucros de uma empresa e seu indicador B/M. Empresas com alto B/M (preço de mercado abaixo do preço contábil) tendem a ter baixo lucro por ação, já empresas com baixo $\mathrm{B} / \mathrm{M}$ (preço de mercado maior que o contábil) tendem a apresentar lucros constantes e lucro por ação mais elevado. Fama e French também desenvolveram uma série de outras pesquisas utilizando indicadores financeiros, com foco para as variáveis tamanho e índice $\mathrm{B} / \mathrm{M}$. A partir destas pesquisas, com ênfase em Fama e French (1992), o campo das finanças adotou o que é chamado de "o modelo dos três fatores de Fama e French". Os fatores do modelo são: (i) o prêmio de risco de mercado (PRM); (ii) prêmio para as ações de valor, ou seja, aquelas com alto índice book-to-market (HML) e (iii) um prêmio para as ações de empresas com baixo valor de mercado $(\mathrm{SMB})^{2}$.

No contex to brasileiro, da Costa Jr. e das Neves (2000) verificaram a influência de três variáveis fundamentais na explicação da rentabilidade média de ações negociadas à vista na Bolsa de Valores de São Paulo (BM\&FBOVESPA). As variáveis estudadas foram valor de mercado, índice preço/lucro e índice valor patrimonial/ preço, além do coeficiente beta. Através do uso de regressões (pelo método SUR) os autores procuraram encontrar se existe influência das variáveis fundamentais analisadas no apreçamento dos ativos no mercado de capitais. Os resultados obtidos eram estatisticamente significativos. De realçar a significância do beta (medida tradicional do risco sistemático na literatura financeira) dentro dos modelos de regressão testados.

Ainda no caso brasileiro, mas considerando os três fatores de Fama e French, Argolo, Leal e Almeida (2012) não encontraram significância estatística para os coeficientes dos fatores HML e SMB (descritos acima). Contudo, o fator PRM (prêmio de risco de mercado, isto é, o beta) apresentou estabilidade e significância estatística.

\section{Análise técnica}

A chamada análise técnica é vastamente utilizada pelos profissionais que atuam no mercado de capitais. Este tipo de análise baseia-se na premissa de que é possível

${ }^{2}$ Para um exemplo de Fama e French utilizando estes três fatores cabe uma consulta a Fama e French (1996). 
identificar comportamentos futuros das variações nos preços de ativos com base na análise dos gráficos destas variações. Além disso, estes analistas costumam utilizar alguns métodos matemáticos (como médias móveis, índices de força relativa, entre outros) para a previsão de tendências futuras. Embora muitas das ferramentas utilizadas neste tipo de análise não tenham sido desenvolvidas a partir de trabalhos científicos, a literatura de finanças está recheada de trabalhos que possuem o intuito de testar a capacidade de previsibilidade destas ferramentas. Nos próximos parágrafos apresentamos alguns destes trabalhos.

Além dos casos onde a análise técnica é aplicada para o mercado de ações, existem casos onde os analistas aplicam este tipo de análise para outros mercados, como mercados futuros e de câmbio, por exemplo. Para o caso do mercado de câmbio, Oberlechner (2001) explica que a análise fundamental é compreendida por aquela que utiliza fundamentos principalmente macroeconômicos de um determinado país que esteja sendo estudado. Já a análise técnica para este caso pode usar muitas ferramentas que são também utilizadas para o mercado de ações, como médias móveis, índices de força relativa, entre outros. Em seu trabalho, Oberlechner (2001) buscou compreender a importância tanto da análise técnica quanto da análise fundamental para investidores do mercado de câmbio em algumas das principais praças da Europa. Utilizando surveys, os resultados do autor indicam que a importância do "grafismo" tem aumentado na década anterior à data de publicação do artigo ou seja, na década dos anos 1990. O autor afirma que, enquanto o analista fundamental baseia suas decisões em informações disponíveis no mercado, isto é, já apuradas, os analistas gráficos baseiam suas decisões em suas próprias conclusões e acreditam que a história que fez os preços se moverem no passado provê indicadores para identificar as oscilações futuras. O autor identificou também que os investidores, na sua maioria, não consideram excludentes as formas de análise técnica e fundamental. No estudo em questão apenas uma pequena minoria de investidores demonstrou um comportamento exclusivo para alguma das duas abordagens de análise e previsão.

Lui e Mole (1998) aplicaram questionários do tipo survey com traders do mercado de câmbio de Hong Kong. Os autores perceberam que mais de $85 \%$ dos respondentes utilizam tanto a análise técnica quanto a análise fundamental para predizer o futuro. No entanto, a escolha da abordagem de análise depende do horizonte de tempo do investimento desejado. Em horizontes curtos de tempo (intraday, semanal e mensal) os autores perceberam a existência de uma preferência pelo uso da análise técnica. Para horizontes mais longos (seis meses, um ano e mais de um ano) 
os investidores apresentaram uma preferência pelo uso da análise fundamental. Os autores não encontraram evidência significativa em termos estatísticos que mostrasse que, na periodicidade de três meses, os investidores tenham preferido uma forma de análise ou outra.

Levy (1967) estudou como índices de força relativa podem servir como critérios para a escolha de investimentos. Na época existia bastante discussão teórica a respeito da hipótese de passeio aleatório (random walk) no mercado de ações. A maioria dos trabalhos testava justamente se algum indicador ou alguma ferramenta seria capaz de explicar as variações nos preços e refutar a hipótese de random walk. Em Levy (1967) o autor afirma que, embora as carteiras e simulações feitas em seu trabalho tenham alcançado retornos superiores ao investir em empresas com maior força relativa nos movimentos de seus preços, não foi possível refutar a hipótese de passeio aleatório. Além disso, o autor percebeu que junto com o retorno mais elevado obtido nas empresas com maior índice de força relativa, ocorreu um risco também mais elevado. Sendo assim, o autor afirma que para que uma estratégia de análise técnica possa produzir retornos maiores do que aqueles que podem ser obtidos por uma seleção aleatória é necessário que o risco não se eleve juntamente com o retorno.

Blume et al. (1994) analisaram o papel que o volume possui em termos de gerar informações a respeito do retorno. Neste contexto, os autores procuraram verificar a aplicabilidade do volume dentro da análise técnica. Blume et al. (1994) afirmam que a análise técnica acredita que o preço e o volume fornecem indicadores de movimentações futuras acerca dos retornos. Os autores comentam que se a hipótese de eficiência de mercado for verdadeira, então tal atividade torna-se inútil. No entanto, se o processo de ajuste dos preços às informações não é imediato, as estatísticas do mercado devem impor informações que ainda não foram incorporadas nos preços. No estudo, os autores supõe que o volume possa servir como um informativo a respeito das variações nos retornos. Os resultados dos autores corroboram com a análise técnica, pois o artigo relata que os traders que utilizaram as informações contidas nas estatísticas de mercado, como preço e volume, obtiveram desempenhos superiores em relação àqueles que não utilizaram.

\section{A pesquisa em finanças com o uso de metodologias multicritério}

As metodologias multicritério são consideradas como uma vertente da Pesquisa Operacional (PO) que tradicionalmente se baseava em um medida monocritério 
de eficiência econômica (Ensslin, Montbeller-Neto, \& Noronha, 2001). A partir da década de 1970 a PO passou a dar ênfase a processos que incorporassem os juízos de valor, os julgamentos preferenciais e os prognósticos de visão de mundo dos decisores (Lyrio, 2008). Com esse novo direcionamento da PO vem à tona duas principais correntes de pensamento multicritério, a saber, a (i) Decision Making - DM; e, a (ii) Decision Aid - DA. Se por um lado a DM buscava desenvolver modelos matemáticos que permitissem descobrir uma decisão ótima que acreditava-se pré-existir, a DA buscava modelar contextos decisionais, a partir das convicções e valores dos tomadores de decisão (Roy, 1990; 1993). A partir de então houve um avanço no uso da MCDA, que, conforme argumentam Figueira, Greco e Ehrgott (2005) tiveram importantes aspectos técnicos ligados a trabalhos clássicos no campo da economia, em particular à economia do bem-estar (welfare economics), da teoria da utilidade e da teoria da escolha social.

No campo das finanças o uso da PO como suporte à decisão já vem de longa data, tendo início na década de 1950, com a introdução da teoria de portfólio de Markowitz. Com o rápido aumento da complexidade das decisões financeiras com o passar das décadas, tornou-se importante o desenvolvimento e implementação de metodologias que dessem suporte à tomada de decisão no campo, nesse sentido, a MCDA proveu aos tomadores de decisão um conjunto de metodologias bem ajustadas às finanças modernas (Spronk, Steuer, \& Zopounidis, 2005).

No caso específico das teoria de portfólio de investimentos, a questão principal a ser tratada pelos tomadores de decisão diz respeito justamente ao problema da seleção de um portfólio, que formulado como um problema de otimização, vem sendo exaustivamente estudado a partir de duas dimensões, a saber, risco e retorno. Por outro lado, para Spronk, Steuer e Zopounidis (2005), a decisão de seleção de um portfólio inclui critérios que vão além do padrão risco/retorno, e assim, a MCDA entra em cena, pois tem em conta os múltiplos objetivos que podem envolver a tomada de decisão, bem como discute os efeitos do reconhecimento de múltiplos critérios na prática da seleção de um portfólio.

A metodologia MCDA, conforme aplicada no presente estudo, apresenta ilustrações no setor financeiro brasileiro, tanto no sentido de avaliação do valor de uma empresa (Lima, Ensslin, Lopes, \& Dutra, 2006), quanto no sentido de gestão do setor financeiro de organizações (Brandalize, 2004; Schnorrenberger, 2005; Rezende, Alencar \& Lyrio, 2011), e de avaliação econômico-financeira de em- 
presas de capital aberto para fins de investimento (Bortoluzzi, Ensslin, Lyrio, \& Ensslin, 2009, 2011).

Em nível internacional também podem ser encontrados trabalhos que se utilizam de metodologias multicritério para fins de tratamento de problemas ligados à finanças. No caso de métodos DM, Xidonas, Mavrotas \& Psarras (2009) se utilizaram do método ELECTRE Tri para seleção de ações utilizando dados advindos de análise financeira (ROA, ROE, margem líquida, prazo médio de recebimento, prazo médio de pagamento, giro do ativo, liquidez seca, liquidez corrente, entre outros), argumentando que foi possível selecionar um conjunto de ações atrativas ao investidor por meio do uso do método. Utilizando-se de métodos DA, foram encontrados trabalhos que abordam a gestão de risco financeiro e análise de crédito (Yu, Wang, \& Lai, 2009; Zopounidis, 2006), bem como trabalhos que lidam com avaliação de desempenho de agências bancárias (Ferreira, Santos, \& Rodrigues, 2010; Ferreira, Spahr, \& Pereira, 2011)

Os estudos supracitados se prestaram a ilustrar diversas aplicações como uso de metodologias multicritério tanto do ponto de vista da DM quanto do ponto de vista da DA, evidenciando o potencial dessas metodologias para fins de tomada de decisão no campo das finanças. O presente estudo dá prosseguimento a estudos ligados à aplicação de metodologias multicritério, aprofundando essa discussão no sentido de propor não somente um modelo de avaliação, mas também de propor uma estratégia de investimento baseada em um modelo de apoio à decisão, a ser utilizada ao longo do tempo com vista ao alcance do objetivo de acumulação de capital no longo prazo.

\section{Metodologia}

A metodologia do presente estudo envolve o (i) enquadramento metodológico da pesquisa; (ii) procedimentos adotados na construção do modelo de apoio à decisão; e, (iii) procedimentos para coleta e análise dos dados.

\section{Enquadramento metodológico da pesquisa}

O presente estudo se configura, em relação à natureza de seus objetivos, como sendo um estudo exploratório e descritivo. Exploratório pois visa proporcionar uma maior familiaridade com o problema em estudo (Gil, 2007), nesse caso materiali- 
zado nos critérios de avaliação propostos no instrumento de intervenção descrito na próxima sub-seção; e descritivo pois, conforme Gil (1999), descreve características de uma população e estabelece relações entre variáveis. As características descritas dizem respeito ao desempenho alcançado pelas ações nos critérios de avaliação propostos; as relações estabelecidas entre as variáveis dizem respeito à relação entre a rentabilidade da carteira de investimentos proposta e a rentabilidade do IBOVESPA, utilizado como benchmarking.

Em relação à abordagem do problema, adota uma abordagem quali-quantitativa. A abordagem qualitativa surge no momento de estruturação do modelo de análise, tendo em vista que considera as preocupações do decisor, expressas qualitativamente, bem como adota técnicas de brainstorming para legitimar o modelo de avaliação perante um painel de especialistas. Para Merrian (1998) este tipo de estudo busca entender o significado de sensações vivenciadas pela experiência humana, nesse caso expressa pela vivência do decisor em relação a experiência com investimentos e a consideração daqueles critérios de avaliação que são considerados relevantes para esse decisor. Por sua vez, a abordagem quantitativa é utilizada tanto na construção do modelo de avaliação (na fase de avaliação), quanto na análise dos resultados, via utilização do CAPM para comparar os retornos obtidos pela carteira de investimentos em relação ao retorno do mercado. O uso da abordagem quantitativa tem por objetivo garantir a precisão dos resultados, bem como permitir sua replicabilidade e análise temporal, preocupações inerentes a esse tipo de pesquisa (Bryman, 1988; Richardson, 1999).

\section{Procedimentos adotados na construção do modelo de apoio à decisão}

Para construção do modelo de apoio à decisão proposto no presente estudo, utilizou-se o processo de apoio à decisão, composto de três fases, a saber, (i) estruturação, (ii) avaliação e (iii) elaboração de recomendações (Bortoluzzi et al., 2011).

A etapa de estruturação envolve, inicialmente, a contextualização do problema, apresentando o ambiente onde este se insere e os atores do processo de avaliação. Em seguida é construída uma estrutura hierárquica na qual são estabelecidos os critério de análise e seu desdobramento até um nível no qual seja possível estabelecer uma escala ordinal de mensuração (Bortoluzzi et al., 2011; Ensslin et al., 2001). 
A fase de avaliação, independente da abordagem multicritério utilizada, envolve inicialmente a realização de uma avaliação local, na qual busca-se estabelecer uma escala cardinal para a escala ordinal anteriormente definida; em seguida, realiza-se uma avaliação global, na qual busca-se agregar as avaliações locais por meio de um critério único de síntese (Bana-e-Costa, Ensslin, Correa, \& Vansnick, 1999).

Finalmente, na fase de recomendações, busca-se utilizar o modelo como base para sugestão de ações potenciais, tanto analisando-se o perfil de impacto (gráfico resultante da análise), quanto a pontuação global e local alcançada por cada alternativa (Bortoluzzi et al., 2009, 2011). No caso do presente estudo, as recomendação se materializam na carteira de ações, bem como no portfólio de acompanhamento sugerido.

\section{Procedimentos para coleta e análise dos dados}

Os dados foram coletados no período referente aos anos de 2012 e 2013 (até Julho), considerando a empresas participantes do IBOVESPA no $1^{\circ}$ quadrimestre de 2013, sendo que essa relação de empresas foi utilizada no decorrer de todo o período de análise para fins de comparação. No que tange aos procedimentos para coleta dos dados, os mesmos foram coletados de duas principais fontes, a saber, (i) economatica, e (ii) gráficos utilizados na análise técnica.

A partir da base de dados economatica foram extraídas as informações referentes ao nível de endividamento total das empresas analisadas (dívida sobre passivo total - D/D+PL), margem líquida (ML), margem EBITDA (lucro antes dos juros, imposto de renda, depreciação e amortização), retorno sobre o patrimônio líquido (ROE), preço sobre lucro (P/L), preço sobre valor patrimonial por ação (P/VPA) e dividend yield (DY), referentes a cada trimestre do período de análise. Além dessas informações, optou-se também por extrair do economatica o Beta das ações, sendo todos os dados exportados para planilhas Excel para posterior tratamento.

Em relação à análise gráfica, optou-se por utilizar gráficos semanais, com "zoom" de 2 anos, com o objetivo de permitir a visualização da tendência na qual cada uma das ações se encontrava, bem como para evitar oscilações de curto prazo que pudessem afetar o desempenho das ações. Foram utilizadas na análise gráfica (i) Índice de Força Relativa - IFR; (ii) Moving Average Convergence Divergence - 
MACD; (iii) as médias móveis exponencial de 9 períodos e aritmética de 21 períodos; e, (iv) tendência da ação no período de análise.

Por fim, com o intuito de incorporar a percepção do mercado em relação às ações, foi utilizado o número de recomendações de compra recebidos por cada ação, extraídos de relatório disponibilizado pela corretora do investidor para o qual o modelo foi construído. Neste relatório são compiladas as carteiras recomendadas de diversas corretoras atuantes no mercado brasileiro, informação que foi utilizada para fins de verificação do consenso do mercado em relação a dada ação.

Finalmente, em relação à implementação da estratégia proposta, foram seguidas as seguintes premissas:

- Utilizar-se de uma estratégia do tipo buy and hold, com o objetivo de acumulação de capital no longo prazo. Nesse sentido, evitou-se a utilização de stop-loss, que poderiam ser acionados devido a repiques no preço das ações no período em que essas estivessem em carteira;

- Manter posições compradas;

- A carteira deve conter entre 5 e 9 ações. Esse tamanho de carteira é justificado com base em Miller (1956) levando em conta a argumentação em relação ao número $7+$ ou -2 , que, conforme o autor, se configura como a limitação humana de processar informações simultâneas. Além disso, utiliza esse número de ações com vista a mitigar o risco não-sistêmico, tendo em conta que uma carteira com 4 ativos já elimina cerca de $70 \%$ desse tipo de risco;

- Para que a ação entre na carteira, esta deverá obter pelo menos 70 pontos na avaliação global proposta pelo modelo de análise, sendo que não se aceita mais de uma ação de um mesmo setor na carteira;

- Nas situações em que existam menos do que 5 ações com pelo menos 70 pontos na avaliação global, insere-se na carteira as ações com pontuação abaixo de 70 pontos, até que se complete o número de 5 ações em carteira (tamanho mínimo);

- No caso de ações ordinárias e preferenciais de uma mesma empresa, optar pelas ações preferenciais;

- Todas ações constantes na carteira possuem a mesma taxa de contribuição, ou seja, tem o mesmo peso; 
- A primeira rodada de avaliação ocorre no início de cada ano, sendo realizada para todas as ações constantes no IBOVESPA no $1^{\circ}$ quadrimestre de 2013. Nesta primeira rodada, monta-se a carteira para o $1^{\circ}$ trimestre do ano e estabelece-se, também, o portfólio de acompanhamento, contendo além das ações que entram em carteira, mais 10 ações que serão acompanhadas no decorrer do ano $^{3}$. Após a primeira rodada, são feitos ajustes trimestrais, rodando novamente o modelo de análise para o conjunto de ações composta pela carteira mais o portfólio de acompanhamento, com vista a monitorizar as oscilações de mercado e ajustar a carteira.

\section{Apresentação e análise dos resultados}

A seção destinada à análise dos dados envolve a apresentação do processo utilizado na construção do modelo de avaliação proposto; em seguida são apresentados os resultados da implementação da estratégia desenvolvida; e, finalmente, são aplicados testes estatísticos para verificação de sua validade.

\section{A construção do modelo de apoio à decisão}

No caso do presente estudo, a $1^{\text {a }}$ fase de construção do modelo, a saber, fase de estruturação, teve início com o estabelecimento, por parte do autor (doravante denominado Decisor) que pretendia utilizar o modelo para fins de apoio às suas decisões de investimento, das áreas de preocupação que este considera no momento de estabelecer uma carteira de ações, conforme sugerido por Kenney (1992). $\mathrm{O}$ decisor argumentou que teria em mente em primeiro lugar os fundamentos das empresas nas quais poderia vir a investir, com vista a evitar empresas problemáticas, bem como aquelas que apesar de se apresentarem em boa situação, estivessem sobreprecificadas. Além da questão dos fundamentos, o decisor externou preocupação com a expectativa do mercado em relação às ações e com a situação gráfica dos ativos, de modo a encontrar um momento adequado para compra. Essas preocupações levantadas pelo decisor são concordantes com o que foi constatado na literatura, sobre o fato de que os investidores, no momento de alocação de seus

\footnotetext{
${ }^{3} \mathrm{Na}$ composição do conjunto de ações a serem acompanhadas no decorrer de um ano, não é permitida a existência de mais do que duas ações de um mesmo setor, com vista a manter esse conjunto diversificado. A importância dessa premissa diz respeito ao fato de que, em determinados momentos, o mercado pode estar favorável a determinado setor, o que levaria a concentração de ações desse setor no conjunto a ser acompanhado, aumentando o nível de risco não-sistêmico.
} 
recursos, tomam em consideração não apenas informações referentes aos fundamentos das empresas, mas também informações gráficas, que permitem uma melhor análise sobre o momento mais adequado para compra de ativos (Lui \& Mole, 1998; Oberlechner, 2001).

Uma vez estabelecidas as preocupações iniciais do decisor, foi realizada reunião de brainstorming, na qual as preocupações foram discutidas por um painel de especialistas composto pelos integrantes da disciplina Avaliação de Investimentos, doutorandos em administração, com linha de pesquisa direcionada à finanças e desenvolvimento econômico. Com a discussão, foi possível organizar as preocupações do decisor em uma estrutura arborescente, na qual as suas preocupações foram desdobradas até um nível no qual fosse possível estabelecer uma escala de avaliação (Ensslin et al., 2001). Pela estrutura arborescente apresentada na Figura 1 é possível perceber que foram utilizados como critérios de avaliação aqueles indicadores considerados importantes pelo decisor, no momento da escolha de seu portfólio. Outros indicadores, bem como outras questões foram apresentadas e discutidas pelo painel de especialistas, sendo incorporadas (ou não) ao modelo de acordo com o perfil/preferências do decisor.

Após a discussão realizada junto ao painel de especialistas, o decisor acabou optando por 13 indicadores que estavam alinhados às suas expectativas no momento da seleção de uma ação para investimento. Dentre os indicadores financeiros, o decisor selecionou o endividamento total, as margens líquida e EBTIDA, bem como o ROE; em relação aos múltiplos, selecionou a relação entre o preço e o lucro por ação $(\mathrm{P} / \mathrm{L})$, a relação entre o preço e o valor patrimonial da ação (P/VPA) e o dividend yeld; em relação às informações de mercado, optou por considerar o Beta da ação e o consenso de mercado, expresso pelo total de recomendações de compra recebido pela ação no período de análise; finalmente, em relação à situação gráfica, o decisor optou por utilizar o nível de convergência / divergência entre as médias exponenciais dos preços das ações, expresso pelo indicador Moving Average Convergence Divergence - MACD, o comportamento das médias exponencial de 9 períodos e aritmética de 21 períodos, bem como a tendência na qual o preço da ação se encontrava. Desta forma o modelo construído atendeu às preocupações do decisor, ao mesmo tempo em que foi sendo legitimado pelo painel de especialistas, em um processo de construção de conhecimento interativo e iterativo. 


\section{Figura 1}

\section{Estrutura arborescente resultante da discussão pelo painel de especialistas}

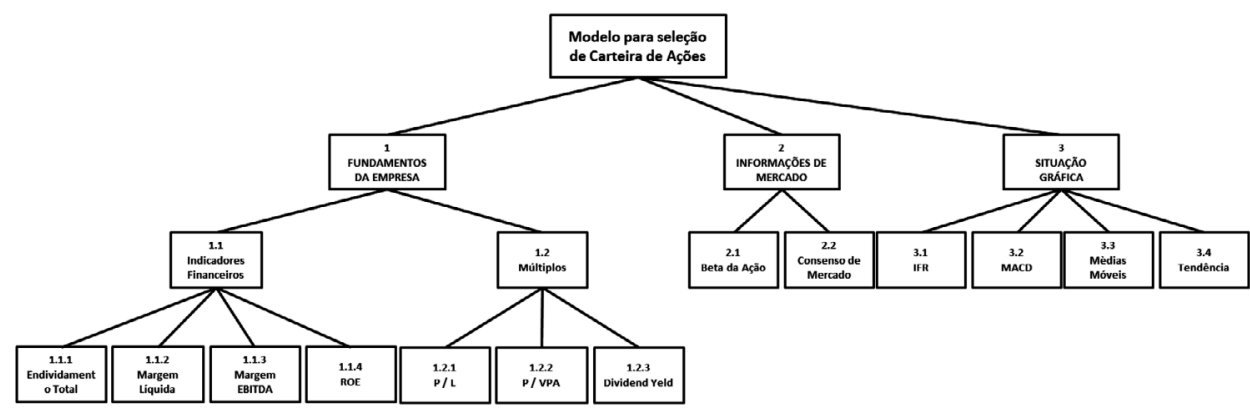

Para finalizar a fase de estruturação, é necessário, ainda, construir os descritores que irão apresentar os possíveis níveis de desempenho de um critério em análise (Ensslin et al., 2001). Um descritor é composto por uma escala, que apresenta o que o descritor pretende medir, um conjunto de níveis de impacto e dois níveis de referência (Bom e Neutro) que possibilitam a comparação entre os diversos descritores que compõem o modelo (Bortoluzzi et al., 2009, 2011; Ensslin et al., 2001). Como ilustração, apresenta-se a Quadro 1, referente ao descritor 1.1.1 Endividamento total.

\section{Quadro 1}

\section{Descritor 1.1.1 - Endividamento total}

\begin{tabular}{|c|c|l|}
\hline Descritor 1.1.1 - Endividamento Total \\
\hline Níveis de Impacto & $\begin{array}{c}\text { Niveis de } \\
\text { Referência }\end{array}$ & Escala Ordinal \\
\hline N5 & & Endividamento total menor ou igual a 20\% \\
\hline N4 & BOM & Endividamento total maior que 20\% e menor ou igual a 35\% \\
\hline N3 & & Endividamento total maior que 35\% e menor ou igual a 50\% \\
\hline N2 & NEUTRO & Endividamento total maior que 50\% e menor ou igual a 65\% \\
\hline N1 & & Endividamento total maior que 65\% \\
\hline Escala: Avaliar o nível de endividamento total da empresa (D / D+PL) \\
\hline
\end{tabular}

A fase de avaliação se inicia com o estabelecimento de uma escala cardinal para as escalas ordinais previamente construídas, ou seja, estabelecer uma escala quantitativa que permita proceder com a avaliação local. Para realizar essa atividade optou-se por utilizar o software MACBETH (Measuring Attractiveness by Categorical Based Evaluation Technique). 
Este software permite ao usuário selecionar, em uma escala semântica que varia de muito fraca a extrema, qual a perda percebida por ele na passagem de um nível de desempenho para outro, imediatamente inferior (Bana-e-Costa \& Chagas, 2004; Bana-e-Costa \& Vansnick, 1997). A figura 3 apresenta a função de valor criada para o descritor 1.1.1 - Endividamento total. Importante salientar que aos níveis Bom e Neutro, são atribuídos, respectivamente, 100 e 0 pontos, sendo que a partir desses dois níveis de referência o software calcula a pontuação dos demais níveis de acordo com as preferências do decisor.

Como evidenciado na figura 2, o decisor considerou a passagem do nível N5 para o nível N4 - sair de uma situação na qual a empresa se encontrava com um nível de endividamento total menor ou igual a $20 \%$ e entrar em uma situação na qual a empresa passaria a ter um nível de endividamento total maior que $20 \%$ e menor ou igual a 35\% - como sendo fraca. A passagem do nível N4 para o nível N3 foi considerada moderada, ou seja, a perda percebida pelo decisor, apesar de não ser extrema, já se apresenta um pouco mais expressiva. Por outro lado, a passagem do nível N3 para o nível N2, que levaria a empresa em análise para um patamar de endividamento total superior a 50\%, foi considerada muito forte, o que demonstra a preocupação do decisor em evitar as ações de empresas com endividamento total superior a 50\%. Finalmente, a passagem do nível N2 para o nível N1 foi considerada muito fraca, pelo fato de o decisor pensar que, uma vez superado o patamar de $50 \%$ de endividamento total, a ação já seria evitada, independentemente do aumento do endividamento da empresa acima desse patamar.

\section{Figura 2}

Função de valor gerada pelo software MACBETH para o descritor 1.1.1 - Endividamento total

\begin{tabular}{|c|c|c|c|c|c|c|c|}
\hline \multicolumn{7}{|c|}{ Endividamento Total } & $\Sigma 3$ \\
\hline 䊫 & N5 & N4 & N3 & N2 & N1 & $\begin{array}{c}\text { Escala } \\
\text { atual }\end{array}$ & \multirow{2}{*}{$\begin{array}{l}\text { extrema } \\
\text { mt. forte }\end{array}$} \\
\hline N5 & nula & fraca & positiva & positiva & positiva & 125.0 & \\
\hline N4 & & nula & moderada & positiva & positiva & 100.0 & Forte \\
\hline N3 & & & nula & mt. forte & positiva & 62.5 & foucta \\
\hline N2 & & & & nula & mt. fraca & 0.0 & mt. fraca \\
\hline N1 & & & & & nula & -12.5 & nula \\
\hline \multicolumn{8}{|c|}{ Julgamentos consistentes } \\
\hline \multicolumn{8}{|l|}{ 思? } \\
\hline
\end{tabular}

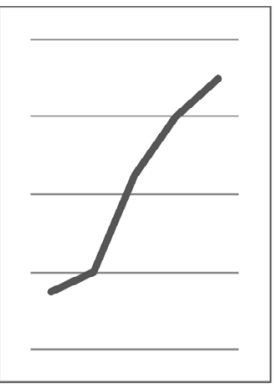

Fonte: M-Macbeth, 2005 
No que concerne à avaliação global, esta envolve o estabelecimento de taxas de compensação que representem a importância relativa de cada um dos critérios de avaliação no modelo. Nessa etapa, optou-se por utilizar o método swing weights (Beinat, 1995; Bodily, 1985; Goodwin \& Wright, 1991; Von-Winterfeldt \& Edwards, 1986). O método consiste em solicitar ao decisor que escolha, considerando-se todos os critérios em nível neutro, em qual critério ele gostaria de saltar para nível bom, sendo a esse critério abribuído 100 pontos. Em seguida solicita-se ao decisor que escolha qual o próximo critério a passar para o nível bom e quanto ele valeria, uma vez que o critério anterior recebeu 100 pontos, repetindo o procedimento até que se esgotem todos os critérios.

Como exemplo, apresenta-se o procedimento para os critérios 1 -fundamentos da empresa; 2 - informações de mercado; e, 3 - situação gráfica. O decisor escolheu dar o primeiro salto no critério 1 -fundamentos da empresa, atribuindo-lhe 100 pontos. Em seguida, decidiu que o segundo salto deveria ocorrer no critério 3 - situação gráfica, mas que esse salto também deveria receber 100 pontos, pois ele acredita ambos os critério terem a mesma importância. Finalmente, resolve atribuir 50 pontos para o critério 2 - informações de mercado. Para que os valores sejam normalizados, deve-se dividir as pontuações de cada critério pelo somatório de todos que, no caso do presente estudo, gerou as seguintes taxas de substituição:

1 - Fundamentos da empresa

$$
\begin{aligned}
& \mathrm{w}_{1}=100 / 250=0,40 \text { ou } 40 \% ; \\
& \mathrm{w}_{2}=50 / 250=0,20 \text { ou } 20 \% ; \\
& \mathrm{w}_{3}=100 / 250=0,40 \text { ou } 40 \% .
\end{aligned}
$$$$
3 \text { - Situação gráfica }
$$

Uma vez finalizada a fase de avaliação, o modelo de apoio à decisão está construído, bastando para finalizar a avaliação, realizar a agregação das avaliações locais por meio de um critério único de síntese, calculado pela seguinte equação:

$$
V(a)=\sum_{i=1}^{i=n} w_{i} x v_{i}
$$

Onde $V(a)=$ Valor do desempenho global; $\boldsymbol{v}_{i}=$ Valor do desempenho local no critério de avaliação; $\boldsymbol{w}_{i}=$ Taxa de substituição no critério de avaliação; $n=$ Número de critérios de avaliação do modelo. 
A figura 3 apresenta o modelo de avaliação construído com o perfil de desempenho referente à avaliação de Cia. Hering S.A. (HGTX3) em 2012 - T01, ação que recebeu a melhor avaliação nesse período. Como pode ser observado, a HGTX3 obteve uma avaliação global de 94 pontos, alavancada pelo desempenho excelente em relação aos descritores 1.1.1 - endividamento total; 1.1.2 - margem líquida; 1.1.4 - ROE; 1.2.1 - P/L; e 2.2 - consenso de mercado. Além disso, todos os descritores referentes à situação gráfica da empresa se encontram em nível bom, o que sugere uma oportunidade de compra de ações dessa empresa.

Figura 3

\section{Modelo construído com o perfil de desempenho de HGTX3}

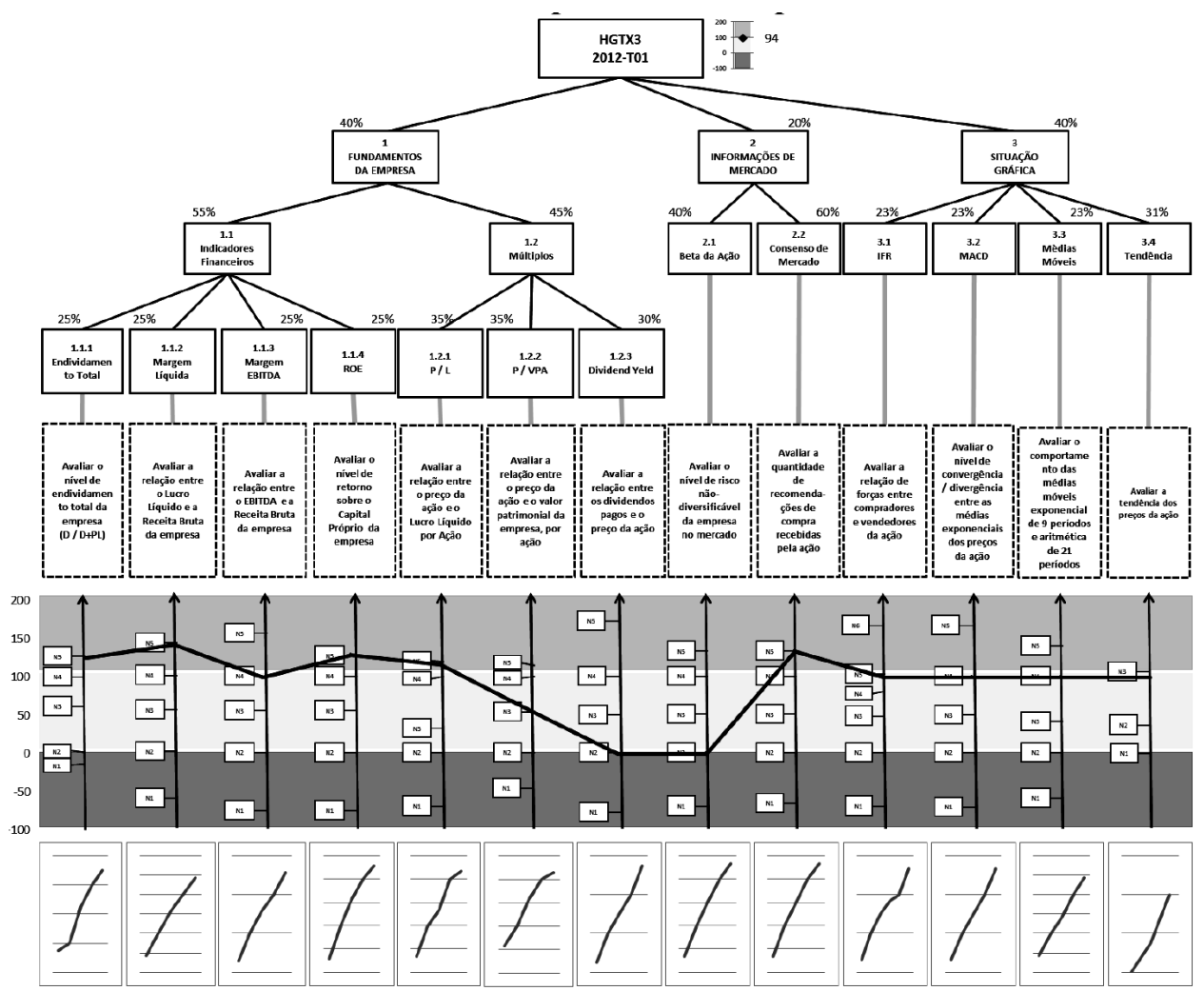

Finalmente, no que diz respeito à fase de recomendações, esta destina-se à sugestão de ações ou alternativas que visem o alcance de um melhor desempenho, geralmente desenvolvidas com base na pontuação global e local obtidas e na análise do perfil de desempenho (Bortoluzzi et al., 2009, 2011; Ensslin et al., 2001). 
No caso do presente estudo, as recomendações consistem na sugestão de portfólio advinda da análise realizada no período. A tabela 1 apresenta o portfólio de acompanhamento gerado pela avaliação para o $1^{\circ}$ trimestre de 2012 . O portfólio de acompanhamento é composto pela carteira sugerida para o trimestre (salientada em cinza), montada com base nas premissas da estratégia de investimento (vide seção 3, metodologia), bem como o conjunto de ações a serem acompanhadas nas rodadas trimestrais de ajuste, no decorrer do ano.

Tabela 1

Portfólio de acompanhamento - 2012 - T01

\begin{tabular}{|c|c|c|c|c|c|c|c|c|c|c|c|c|c|c|c|c|c|c|c|c|c|}
\hline \multicolumn{3}{|c|}{ DADOS DA EMPRESA } & \multicolumn{19}{|c|}{ CRIIÉRIOS DEAVALIAÇ̄̄o } \\
\hline cóo. & EMPRESA & SETOR & 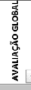 & 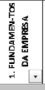 & 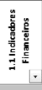 & 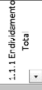 & 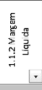 & 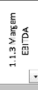 & 。 & 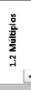 & $\stackrel{\text { aे }}{\mathrm{N}}$ & . & 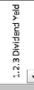 & 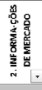 & 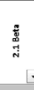 & 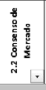 & 施 & 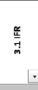 & 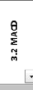 & 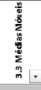 & 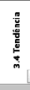 \\
\hline HGIX3 & CIAHERING & Varejo Vestuàtio & 94 & 96 & 124 & 125 & 143 & 100 & 129 & 61 & 117 & 57 & 0 & 80 & 0 & 133 & 100 & 100 & 100 & 100 & 100 \\
\hline VALES & VALE SA-PF & Mineraç̋̆o & 90 & 121 & 138 & 125 & 143 & 157 & 129 & 106 & 117 & 100 & 100 & 120 & 100 & 133 & 11 & 83 & 50 & 43 & 0 \\
\hline CMIG 4 & CEMIG PREF & Encreia & 85 & 95 & 98 & 63 & 100 & 100 & 129 & $x_{1}-x-1$ & 117 & 57 & 100 & 80 & 0 & 133 & 77 & 0 & 100 & 100 & 100 \\
\hline СTPз & CETIP & Bolsas & 83 & 102 & 123 & 63 & 143 & 157 & 129 & 76 & 117 & 100 & 0 & 60 & 0 & 100 & 77 & 0 & 100 & 100 & 100 \\
\hline PDER & PDG RFAITY & Construçāo "Blue Chips" & 83 & 71 & 68 & 100 & 57 & 57 & 57 & 76 & 117 & 100 & 0 & 120 & 100 & 133 & $\pi$ & 167 & 167 & 0 & 0 \\
\hline vivis & TELEF BRASI PREF & Telefonia & 83 & 112 & 117 & 125 & 57 & 157 & 120 & 106 & 117 & 100 & 100 & 33 & 67 & 100 & 79 & 0 & 157 & 43 & 100 \\
\hline CSNA3 & SIO NACIONAL & Siderureia & 81 & ${ }_{93}$ & 107 & 0 & 143 & 157 & 129 & 16 & 117 & 100 & 0 & 83 & 133 & 50 & 69 & 100 & 100 & 100 & 0 \\
\hline PETR4 & PETROBRAS-PREF & Petróleo e Gás & 76 & 86 & 79 & 100 & 57 & 100 & 57 & 96 & 117 & 114 & 50 & 120 & 100 & 133 & 44 & 50 & 100 & 43 & 0 \\
\hline IISAa & "TAUSA-PREF & Bancos "Grande Porte" & 73 & 17 & 14 & 123 & 143 & -31 & 100 & 10 & 100 & 3 & so & 83 & 133 & so & o) & 100 & 100 & 43 & 38 \\
\hline MRVE3 3 & MRV ENGENHARIA & Construçä̈ "Blue Chips" & 80 & 99 & 118 & 100 & 143 & 100 & 129 & 76 & 117 & 100 & 0 & 100 & 50 & 133 & 52 & 83 & 100 & 43 & 0 \\
\hline BVMF3 & BMEFBOVESPASA & Bolsas & 78 & 102 & 106 & 125 & 143 & 157 & 0 & 96 & 117 & 114 & 50 & 50 & 50 & 50 & 69 & 100 & 100 & 100 & 0 \\
\hline CPLEG & COPEL-PREF B & Enersia & 76 & 93 & 96 & 125 & 100 & 100 & 57 & 91 & 117 & 100 & 50 & 80 & 0 & 133 & 58 & 0 & 100 & 100 & 38 \\
\hline TIMP3 & TIM PART & Telefonia & 72 & 53 & 71 & 125 & 0 & 100 & 57 & 32 & 33 & 57 & 0 & 53 & 67 & 139 & 100 & 100 & 100 & 100 & 100 \\
\hline IтUв4 & ITAU UNIBAN PREF & Bancos "Grande Porte" & 72 & 45 & 25 & 13 & 57 & 71 & 129 & 70 & 100 & 57 & so & 133 & 133 & 133 & 67 & 100 & 100 & 43 & 38 \\
\hline CSAN3 3 & $\cos A N$ & Aguicar c Álcool & 72 & 87 & 96 & 100 & 57 & 100 & 120 & 76 & 117 & 100 & 0 & 53 & 67 & 133 & 66 & 50 & 0 & 100 & 100 \\
\hline DTEX] & DURATEXSA & Mntcrial de C.onstruys̄ön & 69 & 71 & 70 & 100 & 57 & 100 & 57 & 62 & 33 & 100 & 50 & 100 & 100 & 100 & 52 & 83 & 100 & 43 & 0 \\
\hline GGBP4 & GLROAU-PREF & Siderurgia & 69 & 53 & 39 & 100 & 0 & 0 & 57 & 10 & 100 & 100 & 0 & 100 & so & 133 & 69 & 100 & 100 & 100 & 0 \\
\hline ARML3 & BRMAILS & shappine center & 65 & 106 & 114 & 100 & 143 & 157 & 57 & 96 & 117 & 114 & 50 & 53 & -67 & 139 & 31 & 0 & 0 & 0 & 100 \\
\hline CIEL3 & CIELO SA & Cartôes & 63 & 76 & 138 & 125 & 143 & 157 & 129 & 0 & 0 & -43 & 50 & 33 & -67 & 100 & $\sigma 6$ & 50 & 0 & 100 & 100 \\
\hline
\end{tabular}

Com a sugestão do portfólio de acompanhamento, finaliza-se o processo de apoio à decisão. Apesar de ter em conta que o modelo apoiou o decisor na organização de suas preocupações em relação à decisão de investimento em ações e propiciou a elaboração de um portfólio de acompanhamento, é preciso verificar se a estratégia de investimento proposta atinge o seu objetivo, a saber, acúmulo de capital no longo prazo. Para tanto, passa-se à próxima seção, que se destina a apresentar os resultados da implementação da estratégia de investimento com base no modelo proposto.

\section{A estratégia de investimento: apresentação e análise dos resultados}

Com intuito de verificar a real aplicabilidade da estratégia de investimento proposta, apresenta-se inicialmente a tabela 2. Esta tabela apresenta, na coluna "perí- 
odo", o trimestre ao qual a carteira se refere; as colunas 1 a 9 apresentam os ativos constantes na carteira do trimestre, ordenados de acordo com a pontuação obtida na análise com base no modelo proposto. As duas últimas colunas apresentam a rentabilidade média da carteira, por trimestre, e a rentabilidade do IBOVESPA no mesmo período, bem como seus respectivos valores acumulados no período de análise.

Relativamente aos resultados trimestrais, conforme observado na tabela 2 , a carteira proposta obteve retorno superior ao IBOVESPA em quase todos os períodos de análise, com exceção do $4^{\circ}$ trimestre de 2012, período em que o IBOVESPA retornou positivamente em $6.63 \%$, contra um retorno de $1.22 \%$ da carteira. A maior rentabilidade da carteira ocorreu no $1^{\circ}$ trimestre de 2012 , quando obteve rentabilidade de $15.77 \%$. Esse foi um trimestre no qual a bolsa brasileira esteve em alta, tendo o IBOVESPA obtido uma rentabilidade positiva de $13.70 \%$. Por outro lado, o pior resultado da carteira foi obtido no $2^{\circ}$ trimestre de 2013 , quando obteve rentabilidade de $-5.36 \%$. Apesar do resultado negativo, a carteira conseguiu se manter acima do IBOV, que obteve rentabilidade de $-15.78 \%$. Especificamente nesse trimestre, a queda acentuada do IBOVESPA em parte é explicada pela queda generalizada das ações do grupo EBX, principalmente os papéis da OGX Petróleo - OGXP3 - que registraram quedas expressivas em seu valor de mercado no período, puxando o índice para baixo.

Tabela 2

Rentabilidade da carteira de investimentos por trimestre e acumulado no período

\begin{tabular}{|c|c|c|c|c|c|c|c|c|c|c|c|}
\hline \multirow{2}{*}{ Período } & \multicolumn{9}{|c|}{ Ação } & \multirow{2}{*}{$\begin{array}{c}\text { Rent. } \\
\text { Média }\end{array}$} & \multirow{2}{*}{$\begin{array}{c}\text { Rent. } \\
\text { IBOVESPA }\end{array}$} \\
\hline & 1 & 2 & 3 & 4 & 5 & 6 & 7 & 8 & 9 & & \\
\hline 2012 & HGTX3 & VALE5 & CMIG4 & CTIP3 & PDGR3 & VIVT4 & CSNA3 & PETR4 & ITSA4 & & \\
\hline T01 & $45.26 \%$ & $9.62 \%$ & $31.08 \%$ & $12.68 \%$ & $6.95 \%$ & $10.05 \%$ & $14.95 \%$ & $10.22 \%$ & $1.10 \%$ & $15.77 \%$ & $13.70 \%$ \\
\hline 2012 & HGTX3 & CMIG4 & VIVT4 & CIEL3 & BRML3 & - & - & - & - & & \\
\hline T02 & $-17.84 \%$ & $11.96 \%$ & $-8.65 \%$ & $14.55 \%$ & $-2.68 \%$ & & & & & $-0.53 \%$ & $-15.74 \%$ \\
\hline 2012 & BVMF3 & BRML3 & HGTX3 & VALE5 & ITUB4 & - & - & - & - & & \\
\hline T03 & $20.78 \%$ & $22.29 \%$ & $20.29 \%$ & $-9.93 \%$ & $9.23 \%$ & & & & & $12.53 \%$ & $8.87 \%$ \\
\hline 2012 & HGTX3 & BVMF3 & BRML3 & PETR4 & DTEX3 & - & - & - & - & & \\
\hline T04 & $-6.82 \%$ & $15,03 \%$ & $-3.91 \%$ & $-7.09 \%$ & $8.87 \%$ & & & & & $1.22 \%$ & $6.63 \%$ \\
\hline 2013 & CMIG4 & VIVT4 & VALE5 & ITUB4 & CIEL3 & BVMF3 & BRML3 & - & - & & \\
\hline T01 & $4.51 \%$ & $13.41 \%$ & $-18.67 \%$ & $9,11 \%$ & $6.83 \%$ & $-2.57 \%$ & $-6.88 \%$ & & & $0.82 \%$ & $-7.55 \%$ \\
\hline 2013 & BVMF3 & CMIG4 & VIVT4 & BBAS3 & CIEL3 & VALE5 & - & - & - & & \\
\hline \multirow[t]{2}{*}{ T02 } & $-7.26 \%$ & $0.75 \%$ & $-4.11 \%$ & $-18.09 \%$ & $12.88 \%$ & $-16.34 \%$ & & & & $-5.36 \%$ & $-15.78 \%$ \\
\hline & & & & & & & & & Acumulado & $25.14 \%$ & $-13.41 \%$ \\
\hline
\end{tabular}


Em relação à composição da carteira, percebeu-se que nos momentos em que a bolsa se encontrava em período de alta a composição da carteira se ampliava, aproximando-se do limite superior (09 ações), enquanto naqueles momentos em que a bolsa se encontrava em períodos de baixa a composição da carteira tendia a se reduzir, aproximando-se do limite inferior (05 ações). Essa característica do portfólio se deve ao fato de que nos momentos de alta da bolsa, um maior número de ações passa a atender às premissas da estratégia; por outro lado, nos momentos de baixa, um menor número de ações atende às premissas da estratégia de investimentos, fazendo com que a carteira se contraia.

Em relação aos resultados acumulados apresenta-se a figura 4, com o comparativo da rentabilidade da carteira e do IBOVESPA no período. Pelo gráfico fica evidenciado que a carteira proposta, após o encerramento do $1^{\circ}$ trimestre de 2012, no qual obteve resultado em linha com o IBOV, passou a apresentar resultado acumulado superior ao IBOVESPA em todo o período de análise. Aliado a essa evidência de rentabilidade superior, salienta-se, ainda, que a carteira não teve rentabilidade negativa no acumulado do período, enquanto o IBOVESPA apresentou rentabilidade negativa em mais de um período. No acumulado geral, a carteira obteve rentabilidade de $25.14 \%$, enquanto o IBOVESPA acumulou perdas de $13.41 \%$ no período, o que leva a crer que a estratégia proposta realmente é capaz de alcançar o objetivo a que se propôs, a saber, obter rentabilidade superior ao IBOVESPA no longo prazo.

\section{Figura 4}

\section{Rentabilidade acumulada Carteira X IBOVESPA}

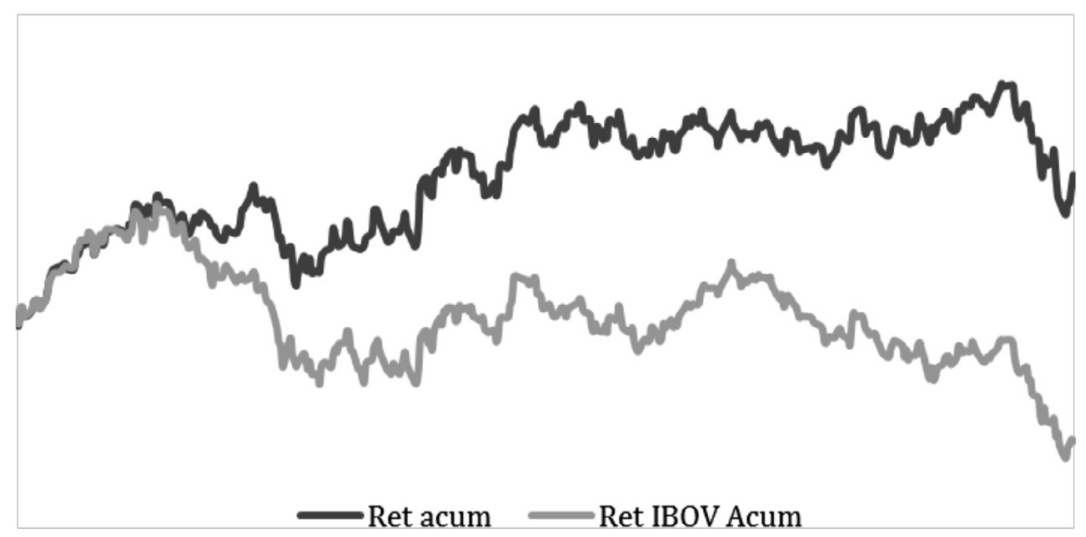




\section{Estimação dos retornos anormais}

Apesar de o gráfico da figura 5 mostrar que, durante o período pesquisado, o desempenho da carteira proposta foi superior ao do IBOVESPA, é necessário mostrar que estes resultados são estatisticamente diferentes, ou seja, não são obra do acaso ou da aleatoriedade. Dessa forma, para fins de comparação dos retornos obtidos na carteira do modelo aqui proposto com os retornos do mercado foi utilizado o modelo CAPM (Capital Asset Pricing Model), já conhecido e bastante difundido na literatura de finanças (Lintner, 1965; Sharpe, 1964), apesar de apresentar algumas limitações, conforme descrito em Fama e French (2004). O CAPM possui variações, no entanto aqui foi utilizada a versão inicial baseada em Sharpe (1964) e em Lintner (1965). Sendo assim, o CAPM é dado por:

$$
E\left(R_{c}\right)=E\left(R_{f}\right)+\left[E\left(R_{m}\right)-E\left(R_{f}\right)\right] \beta_{m}
$$

$E\left(R_{c}\right)$ representa o retorno esperado de um certo ativo ou portfólio. Significa que o retorno esperado de um ativo será a taxa livre de risco $\left(R_{f}\right)$ mais o prêmio $\left[E\left(R_{m}\right)-E\left(R_{f}\right)\right]$ por unidade de risco, medido pelo $\beta$. Alguns anos depois dos trabalhos de Sharpe e Lintner, Jensen (1968) visualizou a possibilidade de realizar uma regressão de série temporal utilizando o CAPM. Esta regressão incluiu o chamado "alfa de Jensen", representado pelo termo de intercepto, ou seja, a constante do modelo de regressão linear simples. Esta constante, apesar de sua simplicidade, desempenha um importante papel na comparação de opções de investimentos, pois é o alfa que mede o retorno anormal de um ativo ou carteira em relação ao seu benchmark. Sendo assim, o CAPM no formato de regressão de série temporal pode ser expresso por:

$$
\left(R_{c, t}-R_{f, t}\right)=\alpha+\beta\left(R_{m, t}-R_{f, t}\right)+\varepsilon_{t}
$$

Onde $R_{c, t}$ é o retorno da carteira no tempo $t ; R_{f, t}$ é o retorno do ativo livre de risco no tempo $t$, aqui representado pela taxa $\mathrm{Selic}^{4} ; R_{m, t}$ é o retorno do mercado no tempo $t$, aqui representado pelo IBOVESPA; $\alpha$ representa o retorno anormal; $\beta$ representa o risco sistêmico e $\varepsilon_{t}$ o termo de erro da regressão linear simples.

\footnotetext{
${ }^{4} \mathrm{~A}$ taxa Selic é anual, isto implica na necessidade de encontrar a taxa equivalente que irá depender da periodicidade dos dados em questão. Para tornar possível a inclusão da Selic no CAPM com dados diários e semanais foi utilizada a seguinte equação: $R_{f, t}=\left[\left(1+\mathrm{R}_{\text {fanual }}\right)^{(1 / n)}(-1)\right]$, onde $n=252$ para dados diários e $n=52$ para dados semanais.
} 
Tabela 3

Retorno anormal CAPM

\begin{tabular}{cccccccc}
\hline & \multicolumn{3}{c}{ Dados Semanais } & & \multicolumn{3}{c}{ Dados Diários } \\
\cline { 2 - 4 } \cline { 6 - 7 } Observações & \multicolumn{3}{c}{78} & & & \multicolumn{3}{c}{368} \\
\hline & Coeficiente & EP & t-stat & & Coeficiente & EP & t-stat \\
\hline $\begin{array}{c}\text { Ret anormal } \alpha \\
\text { Risco sistêmico } \\
\beta\end{array}$ & 0.422 & 0.153 & $2.76 * *$ & & 0.0902 & 0.0322 & $2.80 * * *$ \\
$\mathrm{R}^{2}$ ajustado & 0.757 & 0.061 & $12.49 * * *$ & & 0.7543 & 0.0324 & $23.31 * * *$ \\
\hline
\end{tabular}

*** Significativo à $0.1 \% * *$ Significativo à $1 \%$

Nota: O erro padrão de ambas as regressões (dados diários e semanais) foi corrigido para autocorrelação pelo método de Newey-West, conforme Newey e West (1987).

A tabela 3 apresenta os resultados das regressões realizadas. Com o propósito de conferir a robustez dos resultados, foram realizadas regressões do modelo CAPM tanto com dados semanais quanto diários. Os dados semanais foram escolhidos devido à parte de estruturação do modelo em relação aos critérios de decisão ter sido obtida com o uso de dados semanais, conforme explicado na metodologia. A utilização de dados diários, por sua vez, facilita conclusões estatísticas por aumentar o tamanho da amostra, contudo pode trazer ruídos de curtíssimo prazo às séries e prejudicar a análise. No entanto, os resultados do CAPM apontam para a existência de retorno anormal da carteira aqui proposta tanto para dados diários, quanto para semanais. O teste $t$ realizado nos coeficientes da regressão, cujo propósito é verificar se o coeficiente (tanto $\alpha$ quanto $\beta$ ) é estatisticamente diferente de zero, se mostrou significativo à $1 \%$ para o retorno anormal dos dados semanais e à $0.1 \%$ para o retorno anormal dos dados diários. Além disso, a estatística $t$ foi positiva nos dois casos, indicando a presença de um retorno anormal positivo, ou seja, a carteira aqui proposta superou o seu benchmark. Estes resultados complementam o que já havia sido demonstrado através do gráfico de retornos acumulados exposto na figura 5.

Após alguns anos do surgimento do CAPM a academia apresentou diversas críticas ao modelo, junto com sugestões de modelos mais elaborados. Entre estes modelos presentes na literatura incluem-se o modelo de três fatores de Fama e French e o posterior modelo de cinco fatores dos mesmos autores, por exemplo. Tais modelos surgem aqui como opções de complemento a esta pesquisa para trabalhos posteriores, com o propósito de corroborar com os resultados obtidos através do CAPM em sua forma original. 


\section{Conclusões}

O presente estudo propôs uma estratégia de investimento em ações do tipo Buy \& Hold considerando indicadores de análise técnica e fundamental, bem como as preocupações expressas pelo decisor no momento de seleção de uma carteira. A escolha dos ativos que fariam parte da carteira foi baseada em um método multicritério de apoio à decisão (MCDA). Após escolher os ativos que fariam parte da carteira, os retornos obtidos com a estratégia durante o período analisado foram comparados aos retornos do benchmark (IBOVESPA) durante o mesmo período. Esta comparação foi feita por meio do cálculo dos retornos anormais, medidos pelo coeficiente $\alpha$ do CAPM.

A carteira aqui proposta apresentou retornos significativamente superiores aos do IBOVESPA, o que mostrou que é possível utilizar métodos multicritério para auxiliar no processo de tomada de decisões de investimento, neste caso especificamente na escolha de ações para fazerem parte de um portfólio, o que veio a corroborar com os resultados encontrados em estudos anteriores (Bortoluzzi et al., 2009, 2011; Xidonas, Mavrotas \& Psarras, 2009). O uso de estratégias bem definidas nas decisões de investimento pode auxiliar a evitar a presença de vieses comportamentais e psicológicos presentes no processo de tomada de decisões. Sendo assim, o modelo utilizado pode servir de base para a aplicação de estratégias de investimento em ações.

É importante enfatizar que, embora este estudo tenha testado o modelo proposto com o uso de uma estratégia, esta foi criada de acordo com a percepção de um decisor. Este, por sua vez, pode ser substituído por outro que possua outros parâmetros de análise em relação aos indicadores fundamentais e técnicos aqui utilizados. Consequentemente, uma alteração na estratégia provocaria uma alteração nos retornos da carteira, o que poderia inclusive diminuir o retorno anormal e torná-lo não mais estatisticamente diferente de zero. No entanto, esta pesquisa cumpriu seu objetivo de propor uma estratégia de investimento baseada em métodos MCDA. Além disso, os resultados mostraram que é possível ajustar uma estratégia com parâmetros fundamentados na literatura acadêmica de finanças e obter retornos anormais positivos.

Como propostas para pesquisas futuras é possível ampliar a amostra e utilizar diferentes estratégias com base no mesmo modelo aqui proposto. Além disso, cabe 
para futuro trabalho testar os retornos anormais com base em outros métodos além do CAPM, como por exemplo, o modelo de três fatores de Fama e French.

\section{Referencias}

Argolo, É. B., Leal, R. P., \& Almeida, V. (2012). O modelo de Fama e French é aplicável no Brasil? Relatórios Coppead: 0-27.

Bana-e-Costa, C. A., \& Chagas, M. P. (2004). A career choice problem: an example of how to use MACBETH to build a quantitative value model based on qualitative value judgements. European Journal of Operational Research 153 (2): 232-331.

Bana-e-Costa, C. A., Ensslin, L., Correa, E. C., \& Vansnick, J.-C. (1999). Decision suport systems in action: Integrated aplication in a multicriteria decision aid process. European Journal of Operational Research 113 (2): 315-335.

Bana-e-Costa, C. A., \& Vansnick, J.-C. (1997). Applications of the MACBETH approach in the framework of an additive aggregation model. Journal of Multi-Criteria Decision Analysis 6 (2): 107-114.

Beinat, E. (1995). Multiattribute value functions for environmental management. Amsterdam: Timbergen Institute Research Series.

Blume, L., Easley, D., \& O'hara, M. (1994). Market statistics and technical analysis: The role of volume. Journal of Finance 49 (1): 153-181.

Bodily, S. E. (1985). Modern decision making: a guide to moddeling with decision suport systems. New York: McGraw-Hill.

Bortoluzzi, S. C., Ensslin, S. R., Lyrio, M. V. L., \& Ensslin, L. (2009). Proposta de um Modelo Multicritério de Avaliação de Desempenho Econômico- Financeiro para Apoiar Decisões de Investimentos em Empresas de Capital Aberto. Eletronic Acconunting and Management 03 (03): 92-100. 
Bortoluzzi, S. C., Ensslin, S. R., Lyrio, M. V. L., \& Ensslin, L. (2011). Avaliação de desempenho econômico-financeiro : uma proposta de integração de indicadores contábeis tradicionais por meio da metodologia multicritério de apoio à decisão construtivista ( MCDA-C ). Revista Alcance 18 (2): 200-218.

Brandalize, K. C. D. A. (2004). Metodologia de apoio à decisão construtivista para aperfeiçoamento de processos de faturamento de uma organização. Universidade Federal de Santa Catarina.

Bryman, A. (1988). The nature of quantitative research. In A. Bryman (Ed.), Quantity and quality in social research. London: Unwin Hyman.

Chan, L., Hamao, Y., \& Lakonishok, J. (1991). Fundamentals and stock returns in Japan. Journal of Finance 46 (5): 1739-1764.

Da Costa Jr, N., \& das Neves, M. (2000). Variáveis fundamentalistas e os retornos das ações. Revista Brasileira de Economia 54 (1): 123-137.

Ensslin, L., Montbeller-Neto, G., \& Noronha, S. M. (2001). Apoio à decisão: metodologias para estruturação de problemas e avaliação multicritério de alternativas. Florianópolis: Insular.

Fama, E. F., \& French, K. R. (1988). Dividend Yields and Expected Stock Returns. Journal of Financial Economics 22 (1): 3-25.

Fama, E. F., \& French, K. R. (1992). The Cross-Section of Expected Stock Returns. Journal of Finance 47 (2): 427-465.

Fama, E. F., \& French, K. R. (1995). Size and Book-to-Market Factors in Earnings and Returns. Journal of Finance 50 (1): 131-155.

Fama, E. F., \& French, K. R. (2004). The Capital Asset Pricing Model : Theory and Evidence. Journal of Economic Perspectives 18 (3): 25-46.

Fama, E., \& French, K. (1996). Multifactor explanations of asset pricing anomalies. Journal of Finance 51 (1): 55-84. 
Ferreira, F. A. F., Santos, S. P., \& Rodrigues, P. M. M. (2010). Adding value to bank branch performance evaluation using cognitive maps and MCDA: a case study. Journal of the Operational Research Society 62 (7): 1320-1333.

Ferreira, F. A. F., Spahr, R. W., \& Pereira, J. A. M. (2011). New banking trends, MCDA and financial decisions: insights and a framework for retail banking. Banks and Bank Systems 6 (2): 23-35.

FIgueira, J., Greco, S., \& Ehrgott, M. (2005). Multiple criteria decision analysis: state of art surveys. New York: Springer.

Gil, A. C. (1999). Métodos e técnicas de pesquisa social (5th ed.). São Paulo: Atlas.

Gil, A. C. (2007). Como elaborar projetos de pesquisa (4th ed.). São Paulo: Atlas. Goodwin, P., \& Wright, G. (1991). Decision analysis for management judgement. Chichester: John Wiley \& Sons.

Jensen, M. (1968). The performance of mutual funds in the period 1945-1964. Journal of Finance 23 (2): 389-416.

Kenney, R. L. (1992). Value focused-thinking: a patch to creative decision-making. Cambridge: Harvard University Press.

Levy, R. A. (1967). Relative strength as a criterion for investment selection. Journal of Finance 22 (4): 595-610.

Lima, M. V. A. de, Ensslin, L., Lopes, A. L. M., \& Dutra, A. (2006). Avaliação de empresas de pequeno porte no Brasil através da metodologia construtivista de apoio à decisão MCDA-C. In 30 Encontro da Anpad. Salvador: EnANPAD.

Lintner, J. (1965). The valuation of risk assets and the selection of risky investments in stock portfolios and capital budgets. Review of Economics and Statistics 47 (1): 13-37. 
Lui, Y. H., \& Mole, D. (1998). The use of fundamental and technical analyses by foreign exchange dealers: Hong Kong evidence. Journal of International Money and Finance 17 (3): 535-545.

Lyrio, M. V. L. (2008). Modelo para avaliação de desempenho das Secretarias de Desenvolvimento Regional - SDR's - do Governo do Estado de Santa Catarina: a perspectiva da MCDA-C. Universidade Federal de Santa Catarina.

Merrian, S. B. (1998). Qualitative research and case study applications in education. San Francisco: Jossey-Bass.

Miller, G. A. (1956). The magic number seven, plus or minus two: some limits of our capacity for processing information. The Psychological Review 63 (2): 81-97.

Newey, W., \& West, K. (1987). Hypothesis testing with efficient method of moments estimation. International Economic Review 28 (3): 777-787.

Oberlechner, T. (2001). Importance of technical and fundamental analysis in the European foreign exchange market. International Journal of Finance and Economics 6 (1): 81-93.

Rezende, É. da S. G. de, Alencar, R. de C. B., \& Lyrio, M. V. L. (2011). Proposta de um modelo multicritério de apoio à decisão para cooperativa de crédito a partir de uma perspectiva construtivista. Revista Dos Programas de Mestrado Da Una 16 (04): 61-78.

Richardson, R. J. (1999). Pesquisa Social: métodos e técnicas (3rd ed.). São Paulo: Atlas.

Roy, B. (1990). Decision-aid and decision making. In C. A. Bana-e-Costa (Ed.), Readings in Multiple Criteria Decision Aid (pp. 17-35). Berlin: Springer.

Roy, B. (1993). Decision science or decision-aid science? European Journal of Operational Research 66 (2): 184-203. 
Schnorrenberger, D. (2005). Identificando e avaliando os ativos tangiveis e intangíveis de uma organização visando seu gerenciamento: uma ilustração na área econômico-financeira. Universidade Federal de Santa Catarina.

Sharpe, W. (1964). Capital Asset Prices: a Theory of Market Equilibrium under Conditions of Risk. Journal of Finance 19 (3): 425-442.

Spronk, J., Steuer, R. E., \& Zopounidis, C. (2005). Multicriteria decision aid/analysis in finance. In J. Figueira, S. Greco, \& M. Ehrgott (Eds.), Multiple criteria decision analysis: state of art surveys (pp. 799-857). New York: Springer.

Von-Winterfeldt, D., \& Edwards, W. (1986). Decision analysis and behavioral research. Cambridge: Cambridge University Press.

Xidonas, P., Mavrotas, G., \& Psarras, J. (2009). A multicriteria methodology for equity selection using financial analysis. Computers \& Operations Research 36 (12): 3187-3203.

Yu, L., Wang, S., \& Lai, K. K. (2009). An intelligent-agent-based fuzzy group decision making model for financial multicriteria decision support: The case of credit scoring. European Journal of Operational Research 195 (3): 942-959.

Zellner, A. (1962). An efficient method of estimating seemingly unrelated regressions and tests for aggregation bias. Journal of the American Statistical Association 57 (298): 348-368.

Zopounidis, C. (2006). The use of multicriteria knowledge-based systems in financial risk management. Operational Research 6 (2): 197-219. 
